\title{
Frequencies of human platelet antigens (HPA-1, -2, -3, -4, and -5 ) among the Moroccan blood donors
}

\author{
Zainab Ouabdelmoumene, Houria EL Housse, \\ Fatima Zarati, Nadia Nourichafi, Kamal Bouisk, \\ Mohamed Benajiba, Norddine Habti
}

\begin{abstract}
Aims: Human plateletantigens(HPA) areinvolved in several clinical conditions, such as neonatal alloimmune thrombocytopenia (NAIT), platelet transfusion purpura (PTP), and refractoriness to platelet transfusion.The frequency of platelet antigens varies among populations. So far, typing of HPA systems has not been carried on Moroccan population. The frequencies of these antigens, their risk of alloimmunization, and their clinical implications and complications within Moroccan population are unknown. Our purpose is to define allele frequencies and genotypes in Moroccan population of the five HPA-1 to HPA-5 systems. Evaluate of the risk of anti-platelet alloimmunization among Moroccan blood donors, and estimate the mismatch probability of different platelet alloantigens, after
\end{abstract}

Zainab Ouabdelmoumene ${ }^{1,2}$, Houria EL Housse ${ }^{1,2}$, Fatima Zarati $^{3}$, Nadia Nourichafi ${ }^{3}$, Kamal Bouisk ${ }^{3}$, Mohamed Benaji$\mathrm{ba}^{4}$, Norddine Habti ${ }^{1,2,4}$

Affiliations: ${ }^{1}$ Laboratory of Biotechnology and Experimental Medicine and Biotechnology, Faculty of Medicine and Pharmacy Casablanca University, Hassan II, Morocco; 'Laboratory of Hematology, Genetic and Cell Engineering- Faculty of Medicine and Pharmacy Casablanca - Hassan II University of Casablanca, Morocco; ${ }^{3}$ Regional blood transfusion center of Casablanca, Morocco; ${ }^{4}$ National Blood Transfusion Centre of Rabat, Morocco.

Corresponding Author: Zainab Ouabdelmoumene, Laboratory of Biotechnology and Experimental Medicine, Faculty of Medicine and Pharmacy, University Hassan II, 19 Rue Tarik Ibnou Ziad, B.P. 9154, Casablanca 20000, Morocco; Email: z.ouabdelmoumen@gmail.com

Received: 24 December 2017

Accepted: 06 March 2018

Published: 04 April 2018 random transfusions of platelet concentrates. Methods: The gene polymorphisms of HPA-1, -2, $-3,-4$, and -5 were determined by the PCRSSP technique on a DNA sample of 110 healthy Moroccan blood donors randomly chosen. Results: Alleles frequencies for the HPA systems were: HPA-1a: 0.704, HPA-2a: o.709, HPA3a: 0.773, HPA-4a: 0.99, and HPA-5a: 0.760. The alleles were HPA-1b: 0.296, HPA-2b: 0.291, HPA3b: 0.227, HPA-4b: 0.01, and HPA-5b: 0.240. The theoretical frequencies of descendants at risk of alloimmunization are ranged between $0.99 \%$ for HPA-4 to $20.76 \%$ for HPA-1. The estimated mismatch probability regarding platelet antigens HPA-1, -2, -3, -4, and -5 in Moroccan blood donors, after random platelet transfusion, varies from $1.96 \%$ for HPA-4, to $32.9 \%$ for HPA-1. Conclusion: Taking consideration of the previous studies, and our results, a clinical research associated with platelet disorders, such as: neonatal alloimmune thrombocytopenia (FNAIT), post transfusion purpura (PTP), and, multi-platelet transfusion refractoriness (MPR), are needed to ensure the proper diagnosis and the blood transfusion safety.

Keywords: Alloimmunization, Blood donors, HPA-polymorphism, Moroccan population, Platelet transfusion

\section{How to cite this article}

Ouabdelmoumene Z, El housse H, Zarati F, Nourichafi N, Bouisk K, Benajiba M, Habti N. Frequencies of human platelet antigens (HPA-1, -2, -3, -4, and -5) among the Moroccan blood donors. Int J Blood Transfus Immunohematol 2018;8:100038Zo2ZO2018.

Article ID: 100038Zo2ZO2018 


\section{EDORIUM Journals}

Int J Blood Transfus Immunohematol 2018;8:100038Z02ZO2018. www.ijbti.com

$* * * * * * * * *$

doi: 10.5348/100038Zo2ZO20180A

\section{INTRODUCTION}

Platelets are small $(\sim 1-2 \mu \mathrm{M})$ anucleate discoid cells that are abundantly $(150 \mathrm{000}-450 \mathrm{000} / \mu \mathrm{l})$ present in blood during normal health. They are most well known for their role in haemostasis, in which they adhere to damaged blood vessels, aggregate in mass and through cross-links with fibrinogen form a fibrin clot to prevent further blood loss, but they have been reported to also play roles in inflammation [1] innate and adaptive immunity [2] and in diseases ranging from heart disease to autoimmunity and even cancer [1]. Platelets perform these functions through ligand-receptor interactions involving the many glycoproteins (GP) expressed on their cell surface membranes.

Human platelet antigens (HPA) are polymorphic structures located on platelet membrane glycoproteins [3].

HPA were first described in the late 1950 s and early 1960s [4]. To date, 35 HPAs expressed on six different platelet glycoproteins, GPIIb, GPIIIa, GPIba, GPIbb, GPIa and CD109, have been described [5]. For a current list, see (http://www.ebi.ac.uk/ipd/hpa/table1.html). HPA systems are classified into six biallelic systems, HPA-1, HPA-2, HPA-3, HPA-4, HPA-5, and HPA-15, and the other twenty three systems are monoallelic [6], all of which, were formed by single amino acid substitution, caused by a single nucleotide polymorphism (SNP) in the genes that encode them [7]. One exception is the platelet alloantigen HPA-14, which is formed by one amino acid deletion [8]. The amino acid changes resulting from these SNPs induce changes in glycoprotein structure to form antigens that can elicit antibodies through exposure from pregnancy or platelet transfusions [9].

Antibodies formed against human platelet alloantigens (HPAs) have been reported to contribute to clinical complications of varying severity among different populations $[10,11]$. HPA are the target of platelet alloantibodies that mediate platelet destruction in neonatal alloimmune thrombocytopenia (NAIT), posttransfusion purpura (PTP) [12], and platelet transfusion refractoriness (PTR) [13, 14]. The presence of antiplatelet antibodies due to an incompatibility between platelet donor and recipient, or between mother and fetus during pregnancy is associated to platelet destruction and consequently resulting in severe hemorrhagic diseases $[15,16]$. HPA are inherited by autosomal co-dominance. The risk of alloimmunization depends largely on antigen frequencies, which vary between different populations [17].

The majority of recognized HPAs are expressed on GPIIIa. This glycoprotein appears to be the most immunogenic of the platelet glycoproteins, perhaps related to the high density of GPIIb/ IIIa on the platelet surface with $\sim 80$,000 molecules expressed per platelet. Epitopes on GPIIb/IIIa are the most frequent targets of antibodies detected in all immune platelet disorders [9].

In Caucasians, antibodies to HPA-1 are the most important cause of NATP [18]. Anti-HPA-1a is reported to account for $78 \%$ of cases, followed by anti-HPA- $5 \mathrm{~b}$ in $20 \%$ and anti-HPA-3a in about $3 \%$ of cases $[7,19]$.

The HPA-4b antigen is very rare in Caucasians, but more frequent in Asian populations, in which anti-HPA4a and anti-HPA-4b are more commonly implicated in alloimmune platelet disorder.

Studies of population genetics, point to a heterogeneous diversity of HPA genotypes, in different geographic groups. To date, no data has been reported for HPA-1 to - 5 alleles in Moroccans, except Moroccan Berber Population [19].

As the distribution of HPA varies between ethnic groups and in different geographical locations [5] studying the frequency of HPA in each population, will help in understanding the association between the alloimmunization to these antigens and its clinical consequences. Such information is equally important for the correct diagnosis and the administration of a safe transfusion therapy.

The aim of this study was to investigate the gene frequencies of the 5 platelets antigens HPA-1 to HPA5 in Moroccans blood donors employing DNA typing methods. The collective results were also analyzed to evaluate the mismatch probabilities after transfusion of incompatible platelets in Moroccan population

\section{MATERIALS AND METHODS}

In the beginning of the study we took as reference the number of samples adopted by population in similar countries such as moroccan berbers, Tunisia and Saudi Arabia, who used a hundred subjects in their studies.

The number of samples has been confirmed by a specialized statistician using the method described by Stephen et al. 2013 [20] for the Sample Size Required per Group When Using the Chi-Squared Statistic.

110 aliquots of $5 \mathrm{~mL}$ EDTA-anticoagulated blood samples were collected randomly, from unrelated healthy Moroccan voluntary blood donors at the Regional Blood Transfusion Center of Casablanca, Morocco (CRTS). DNA was extracted using QIAamp DNA Blood Mini Kit (QIAGEN, France) according to the manufacturer's instructions and quantified by optical density measurement with Nanodrop 1000 (Nanodrop Technologies, Wilmington, DE, USA). DNA was stored at $-2 \mathrm{O}^{\circ} \mathrm{C}$. Platelet genotypes for the HPA-1, HPA-2, HPA3, HPA-4, and HPA-5 systems were identified using sequence-specific primer polymerase chain reaction (PCR-SSP) as previously described [21]. All PCR reactions contained two other primers that amplify a region of the 


\section{EDORIUM Journals}

human growth hormone gene (HGH), used as a DNA extraction and amplification controls (Table 1).

In a total reaction volume of $25 \mathrm{ul}$ containing $200 \mathrm{ng}$ genomic DNA, amplification was performed by using an automated thermocycler (9700, PerkinElmer, Foster City, CA, USA) which was programmed for the HPA-1 to -5 as follows:

$10 \mu \mathrm{L}$ of each amplified PCR product were run on a standard 1\% agarose gel electrophoresis (UltraPure agarose, Invitrogen). For each polymorphic position, one or two possible patterns might be observed: $a$ or $b$ genotype. Samples were classified as HPA a/a, a/b, or $\mathrm{b} / \mathrm{b}$ genotypes. The presence of a 429-bp fragment of the human growth hormone gene indicated that amplification took place (positive internal control).

The frequency of HPA genotypes in Moroccan blood donors was calculated by direct counting, from the Microsoft Excel data sheet. The expected genotype frequencies were calculated according to HardyWeinberg law as follows: if frequency of a particular HPA-a allele is $\mathrm{p}$, and the corresponding HPA-b allele is $\mathrm{q}$, then the expected genotype frequencies of $\mathrm{a} / \mathrm{a}, \mathrm{a} / \mathrm{b}$ and $\mathrm{b} / \mathrm{b}$ will be p2, 2pq and q2, respectively.

Consistency of the observed and expected genotype frequencies with the Hardy-Weinberg equilibrium was tested by using the $\chi 2$ test. If the number of any variable was $<5$, Fischer's exact test was used to determine the $\mathrm{P}$ value. The P-value was calculated from the "P Value from Chi-square Calculator": http://www.socscistatistics. com/pvalues/chidistribution.aspx Comparison between the gene frequencies of Moroccan blood with different world races were done with the help of $\chi^{2}$ test.

Mismatch probability of different platelet alloantigens, after random transfusions of blood or platelet concentrates was calculated [22] by using the formula: a2 (1-a2) + b2 (1-b2) or $2 a b(1-a b)$, where $a$ and $b$, are the respective HPA allele's frequencies.

Blood donors agreed to participate in this study by signing an informed consent form. The study was performed according to the guiding principles of the Declaration of Helsinki. The study was evaluated and approved by the Medical Ethic Committee, Faculty of Medicine and Pharmacy of Casablanca.

Table 1: Primer sequences for HPA-1 to -5 for PCR-SSP (20)

\begin{tabular}{|c|c|c|c|c|c|}
\hline & & & & Final primer & Allele \\
\hline \multirow[t]{2}{*}{ HPA } & Specificity & Amorces : sens 5' - $\mathbf{3}$ & $\operatorname{Tm}^{\circ} \mathbf{C}$ & concentration & product \\
\hline & & & & $(\mu \mathrm{M} / \mu \mathbf{l})$ & size (bp) \\
\hline \multirow{3}{*}{ HPA-1 } & HPA-1a & $5^{\prime}$ TCACAGCGAGGTGAGGCCA $3^{\prime}$ & & & \\
\hline & HPA-1b & $5^{\prime}$ TCACAGCGAGGTGAGGCCG 3' & 60 & 0,35 & 90 \\
\hline & Common & 5' GGAGGTAGAGAGTCGCCATAG 3' & & & \\
\hline \multirow{3}{*}{ HPA-2 } & HPA-2a & $5^{\prime}$ GCCCCCAGGGCTCCTGAC $3^{\prime}$ & & & \\
\hline & HPA-2b & 5' GCCCCCAGGGCTCCTGAT 3' & 58 & 0,35 & 258 \\
\hline & Common & $5^{\prime}$ TCAGCATTGTCCTGCAGCCA $3^{\prime}$ & & & \\
\hline \multirow{3}{*}{ HPA-3 } & HPA-3a & 5'TGGACTGGGGGCTGCCCAT 3' & & & \\
\hline & HPA-3b & $5^{\prime}$ TGGACTGGGGGCTGCCCAG 3' & 62 & 0,5 & 267 \\
\hline & Common & $5^{\prime}$ TCCATGTTCACTTGAAGTGCT 3' & & & \\
\hline \multirow{3}{*}{ HPA-4 } & HPA-4a & $5^{\prime}$ GCTGGCCACCCAGATGCG 3' & & & \\
\hline & $\mathrm{HPA}-4 \mathrm{~b}$ & $5^{\prime}$ GCTGGCCACCCAGATGCA 3' & 58 & 0,35 & 120 \\
\hline & Common & 5'CAGGGGTTTTCGAGGGCCT 3' & & & \\
\hline \multirow{3}{*}{ HPA-5 } & HPA-5a & $5^{\prime}$ AGTCTACCTGTTTACTATCAAAG 3' & & & \\
\hline & $\mathrm{HPA}-5 \mathrm{~b}$ & $5^{\prime}$ AGTCTACCTGTTTACTATCAAAA 3' & 58 & 0,5 & 246 \\
\hline & Common & 5' CTCTCATGGAAAATGGCAGTA 3' & & & \\
\hline Positive & $\mathrm{HGH}$ & 5' GCCTTCCCAACCATTCCCTTA 3' & 60 & & \\
\hline Controls & $\mathrm{HGH}$ & $5^{\prime}$ TCACGGATTTCTGTTGTGTTTC $3^{\prime}$ & & 0,2 & 429 \\
\hline
\end{tabular}




\section{EDORIUM Journals}

Int J Blood Transfus Immunohematol 2018;8:100038Z02ZO2018. www.ijbti.com

\section{RESULTS}

HPA-1, -2, - $3,-4$ and 5 systems were genotyped among 110 healthy unrelated blood donors from Regional Blood Transfusion Center of Casablanca. Tables 2, 3 and 4 show the HPA genotypes and alleles frequency of the HPA-1 to -5 systems, observed in Moroccan blood donors. There is no significant deviation from the Hardy-Weinberg equilibrium in any of the systems studied in these populations. The three genotypes $(\mathrm{a} / \mathrm{a}, \mathrm{a} / \mathrm{b}$ and $\mathrm{b} / \mathrm{b})$ were found in all the HPA systems evaluated. With exception of the HPA-4, we noticed the absence of the genotype $\mathrm{b} / \mathrm{b}$ ) for this HPA system. The most frequent genotype among all HPA systems was the homozygous (a/a).

In the present study (Table 3), the allelic frequencies of the a allele, are for the HPA-1 (0.704), HPA-2 (0.709), HPA-3 (0.773), HPA-4 (0.99) and HPA-5 (0.759) systems.

The genotypes, allele frequency, $\mathrm{Chi}^{2}$ and $\mathrm{P}$-value of the Hardy-Weinberg test of samples employed in the study are shown in (Table 4).

For the HPA-1 system, the 1a/1a genotype is the most predominant (51.81\%) followed by $1 \mathrm{a} / 1 \mathrm{~b}(37.27 \%)$ and $1 \mathrm{~b} / 1 \mathrm{~b}(10.90 \%)$ (Table 4$)$. In about 110 unrelated Moroccan individuals, the allele frequencies of $1 \mathrm{a}$ and
$1 \mathrm{~b}$ were calculated to be 0.704 and 0.296 , respectively (Table 3). Table 5 describes the allele frequencies of HPA systems from HPA- 1 to -5 , with those previously reported in other ethnic populations.

Different allele frequencies of the five HPA systems and 2 or the Fisher's exact test values are shown in (table 4). The mismatch probability of HPA after random platelet cell transfusions ranged from 1.96 to $32.9 \%$, with the highest chances of mismatch occurring in case of HPA-1. As just two individuals were heterozygous for HPA-4, there was the lowest chance of mismatch to this HPA. The chances of mismatch to HPA-2, -3 and -5 between Moroccan blood donors are 32.27, 28.87 and 29.82\% (Table 4).

Comparison of allele frequencies of Moroccan blood donors and other populations are shown in Table 5.

\section{DISCUSSION}

The allelic frequencies of HPA systems in 110 blood donors in Morocco showed that the a allele is more frequent than the $\mathrm{b}$ allele for the five studied HPA systems, HPA-1 (a: 0.704 / b: 0.296), HPA-2 (a: 0.709

Table 2: Frequencies of the molecular genotypes of HPA-1 to -5 systems in Moroccan blood donors

$\begin{array}{lccccc}\text { System } & \text { HPA-1 } & \text { HPA-2 } & \text { HPA-3 } & \text { HPA-4 HPA-5 } \\ \text { Genotype } & & & & & \\ & 57 & 54 & 65 & 108 & 60 \\ \text { N (a/a) } & 41 & 48 & 40 & 57 & 0 \\ \text { N(a/b) } & 12 & 8 & 110 & 3 \\ \text { N(b/b) } & & & 5 & \end{array}$

$\mathrm{N}$ : number of donors with the molecular genotype

Table 3: Allele Frequencies of HPA-1 to -5 systems in Moroccan blood donors

\begin{tabular}{|c|c|c|c|c|c|}
\hline \multicolumn{6}{|c|}{ System } \\
\hline Allele & HPA-1 & HPA-2 & HPA-3 & HPA-4 & HPA-5 \\
\hline A & 0.704 & 0.709 & 0.773 & 0,99 & 0.760 \\
\hline B & 0.296 & 0.291 & 0.227 & 0,01 & 0.240 \\
\hline $\mathrm{p}+\mathrm{q}$ & 1 & 1 & 1 & 1 & 1 \\
\hline \multicolumn{2}{|c|}{$\mathrm{p}=\mathrm{a}$ allele frequency } & & & \multicolumn{2}{|c|}{$\mathrm{q}=\mathrm{b}$ allele frequency } \\
\hline
\end{tabular}

For the HPA-1 system, the 1a/1a genotype is the most predominant (51.81\%) followed by 1a/1b (37.27\%) and 1b/1b (10.90\%) (Table 3). In about 110 unrelated Moroccan individuals, the allele frequencies of $1 \mathrm{a}$ and $1 \mathrm{~b}$ were calculated to be 0.704 and 0.296 , respectively (Table 3).

Table 5 describes the allele frequencies of HPA systems from HPA-1 to -5, with those previously reported in other ethnic populations. 


\section{EDORIUM Journals}

Int J Blood Transfus Immunohematol 2018;8:100038Z02ZO2018.

www.ijbti.com

Table 4: Alleles and genotypes frequency of HPA-1 to -5 systems in Moroccan blood donors

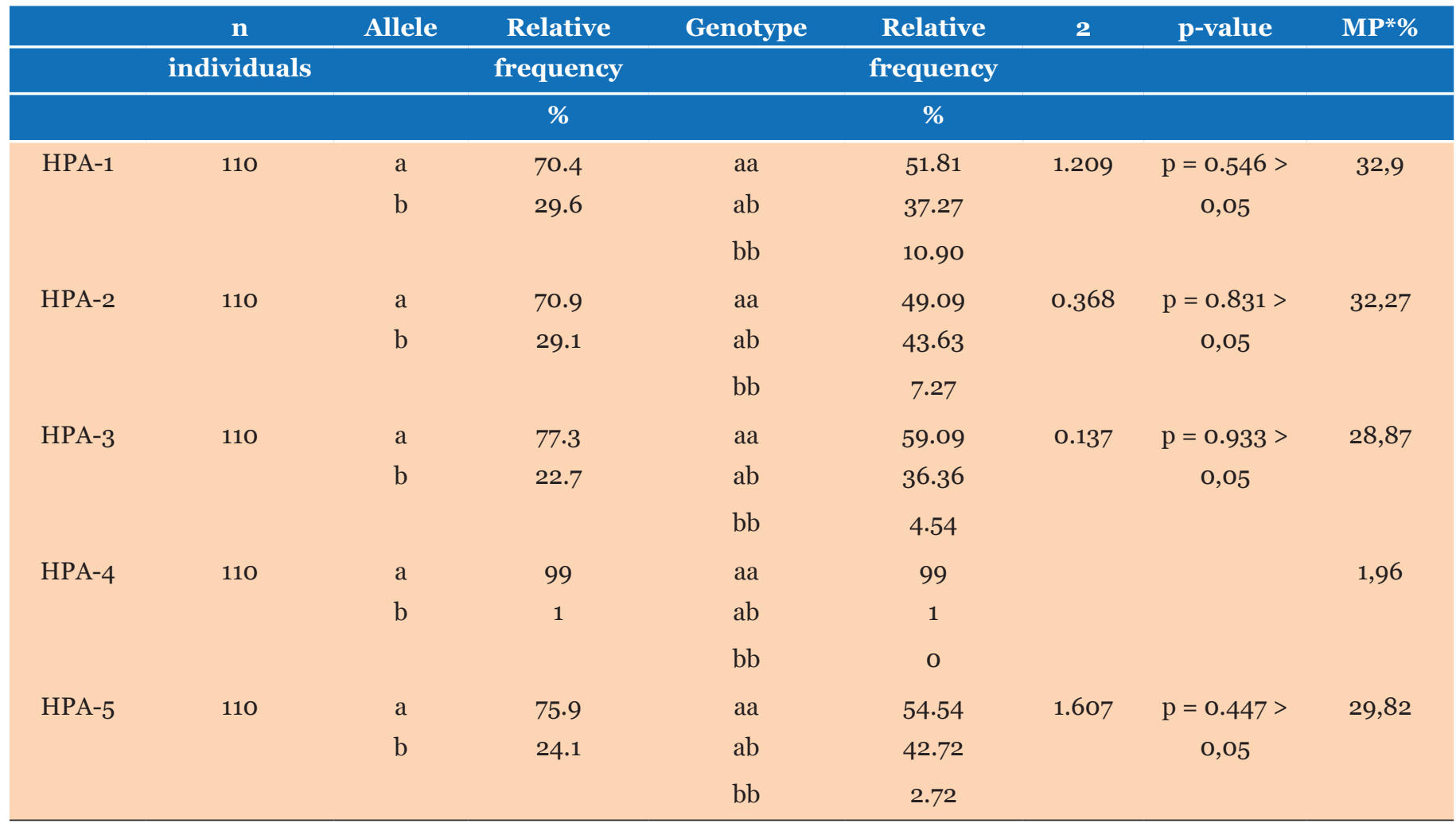

*MP, calculated mismatch probability in random transfusion $=a 2(1-a 2)+b 2(1-b 2)=2 a b(1-a b)$.

Table 5: Comparison of allele's frequencies of Moroccan blood donors and other populations

\begin{tabular}{|c|c|c|c|c|c|c|c|}
\hline \multirow[t]{2}{*}{ Population } & \multirow{2}{*}{\multicolumn{2}{|c|}{$\begin{array}{c}\text { HPA } \\
1 \mathbf{a}\end{array}$}} & \multirow{2}{*}{$\begin{array}{c}\text { HPA } \\
\mathbf{2 a}\end{array}$} & \multirow{2}{*}{$\begin{array}{c}\text { HPA } \\
\mathbf{3 a}\end{array}$} & \multirow{2}{*}{$\begin{array}{c}\text { HPA } \\
\mathbf{4 a}\end{array}$} & \multirow{2}{*}{$\begin{array}{c}\text { HPA } \\
\mathbf{5 a}\end{array}$} & \multirow{2}{*}{$\begin{array}{c}\text { HPA } \\
\text { 15a }\end{array}$} \\
\hline & & & & & & & \\
\hline \multirow[t]{2}{*}{ This work } & & 0.704 & 0.709 & 0.773 & 0,99 & 0.760 & 0.515 \\
\hline & $\mathrm{F}(\mathrm{a})$ & 0.747 & 0.817 & 0.682 & & 0.862 & \\
\hline \multirow[t]{3}{*}{ Moroccan Berber [19] * } & $x^{2}$ & 0.56 & 3.616 & 2.29 & & 3.625 & \\
\hline & $\mathrm{p}$ & 0.454 & 0.057 & 0.130 & 1.000 & 0.057 & \\
\hline & $\mathrm{F}(\mathrm{a})$ & 0.835 & 0.835 & 0.630 & & 0.843 & 0.530 \\
\hline \multirow[t]{3}{*}{ Algeria [33] * } & $x^{2}$ & 9.167 & 9.296 & 7.98 & & 3.963 & 0.046 \\
\hline & $\mathrm{p}$ & 0.002 & 0.002 & 0.004 & 1.000 & 0.046 & 0.830 \\
\hline & $\mathrm{F}(\mathrm{a})$ & 0.780 & 0.860 & 0.750 & & 0.800 & 0.510 \\
\hline \multirow[t]{3}{*}{ Tunisia [34] * } & $x^{2}$ & 1.464 & 7.873 & 0.140 & & 0.47 & 0.018 \\
\hline & $\mathrm{p}$ & 0.226 & 0.005 & 0.708 & 1.000 & 0.492 & 0.893 \\
\hline & $\mathrm{F}(\mathrm{a})$ & 0.904 & 0.776 & 0.596 & & 0.732 & 0.701 \\
\hline \multirow[t]{3}{*}{ Congo $[26] *$} & $x^{2}$ & 16.41 & 1.27 & 8.59 & & 0.523 & $7 \cdot 717$ \\
\hline & $\mathrm{p}$ & $<0.01$ & 0.259 & 0.003 & 1 & 0.469 & 0.005 \\
\hline & $\mathrm{F}(\mathrm{a})$ & 0.907 & 0.763 & 0.614 & & 0.746 & 0.698 \\
\hline \multirow[t]{3}{*}{ Cameroon $[26]$ * } & $x^{2}$ & 15.63 & 0.829 & 7.003 & & 0.085 & 7.23 \\
\hline & $\mathrm{p}$ & $<0.01$ & 0.325 & 0.008 & 1 & 0.770 & 0.007 \\
\hline & $\mathrm{F}(\mathrm{a})$ & 0.800 & 0.710 & 0.650 & & 0.800 & 0.47 \\
\hline \multirow[t]{2}{*}{ Saudi Arabia [5] } & $x^{2}$ & 2.75 & $<0.01$ & 3.847 & 0.990 & 0.394 & 0.405 \\
\hline & $\mathrm{p}$ & 0.097 & $>0.95$ & 0.049 & & 0.530 & 0.524 \\
\hline
\end{tabular}




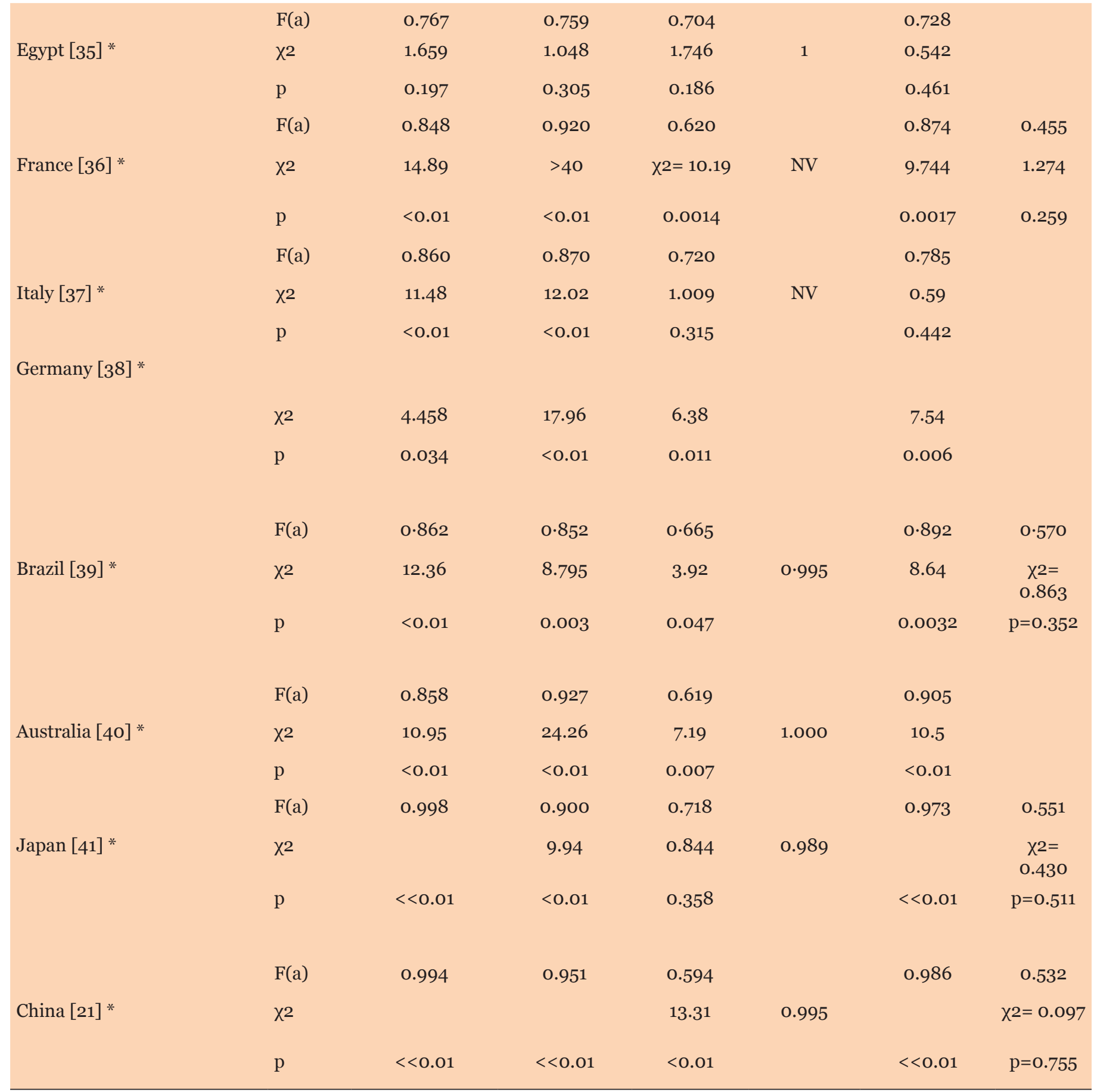

*: reference

/ b: 0.291), HPA-3 (a: 0.773 / b: 0.227), and HPA-5 (a: 0.760 / b: 0.240). On the other hand, the frequency of the $b$ allele for the HPA-4 system is very low compared to other systems.

Our results showed that Moroccan blood donors are polymorphic for four HPA systems (HPA-1, -2, -3, and -5 ), and is almost monomorphic for HPA-4.

According to our results, the degree of HPA-1 system polymorphism (a: 0.704 / b: 0.296) is considered the highest. In case of transfusion and in pregnancy, the degree of polymorphism in an antigenic system directly influences the risk of alloimmunization, a highly polymorphic system has a high risk of alloimmunization [23]. The studying the polymorphisms of the different systems of HPA makes it possible to predict the risk of all immunization in transfusion [24].

Compared to other populations, our results for HPA1 allele frequencies, are significantly different from Caucasians ( $p<0.03$ ), but similar ( $p>0.05$ ) to those of Tunisia, Saudi Arabia and Egypt. The Egyptian study 


\section{EDORiUM Journals}

of Husebekk, et al. showed that among 6974 pregnant women, 23 HPA-1bb women, developed anti-HPA-1a antibodies. The rate of HPA-1a alloimmunisation was found comparable, to Caucasian populations. Severe thrombocytopenia was found in 2 newborns [25]. Thus, and due to the high risk of NAIT and PTP in homozygous HPA-1b/b women, Flug et al. proposed that all pregnant women should be typed for the HPA-1 system.

The allelic frequencies of the HPA-2 system (a: 0.709, b: 0.291) within blood donors showed a high degree of polymorphism, also the polymorphism of this antigen is located on GPIb / IX, the second most abundant glycoprotein complex on the platelet membrane; which may increase the risk of alloimmunization [26]. This was confirmed by calculating mismatch probability of developing an antiplatelet's alloimmunization in case of platelet transfusion between the subjects of this study, which was $32.27 \%$ for HPA-2. We observed that our data for HPA-2 system, were significantly similar ( $\mathrm{p}>0.05$ ) to those of Africans [27] and Arabs (Egypt, Saudi Arabia).

For the HPA-3 system, in Caucasians, approximately $3 \%$ of NAIT neonatal alloimmune thrombocytopenias are due to anti-HPA-3 alloimmunization [18] However, even if this can happen in rare cases, but it is still associated with severe cases of NAIT [28].

Regarding HPA-4, the most remarkable result is that we found a rare genotype HPA-4a/b (1\%). The probability of alloimmunization is very low (1.96\%) compared to other HPA systems. The HPA-4b allele is not common among Moroccans, Caucasians or Arabs, but very common among Asians [29]. The Asian genetic contribution in Moroccan population has been proved by several studies concerning other blood group systems such as the ABO system [30]. Still, the homozygote HPA-4b/b, was not found in our study, suggesting that the risk of antiplatelet alloimmunization in this system is almost zero.

The HPA-5 system mismatch probability in our study was 29.82\%, However HPA-5 is considered as the second immunogenic factor after HPA-1, related to alloimmune syndromes and transfusion-refractory states within Caucasians [31, 32].

The results obtained in Moroccan blood donors have shown that the allelic frequencies of the five HPA systems are significantly similar $(0.05<\mathrm{p}<0.46)$ to those found in a population of Moroccan Berbers from the Amizmiz region, previously described [19]. Berbers lived in areas from Egypt to the Atlantic and from the Niger River to the Mediterranean, so the similarities of distribution could be explained by the genetic contribution of the Moroccan Berbers to the entire Moroccan population.

Morocco occupies a geographical area between the Mediterranean in the North, the Atlantic in the West and it tends towards the South through the Great Sahara and Sub-Saharan Africa. Thus, Morocco experienced various migratory movements throughout its history that have had a genetic impact on its population. Genetic mixing reduces endogamy resulting in genetic variability and increased heterozygosity.
The heterogeneity noted in the allelic distribution of HPA systems predicts a high risk of antiplatelet alloimmunization. It will be then very useful to undertake further investigations completing this work within polytransfused patients and within mothers of thrombocytopenic newborns, and / or within patients with history of platelet incompatibility.

Combined genotypic and serological exploration should also involve the most polymorphic HPA systems.

\section{CONCLUSION}

This analysis of HPA-1 to HPA-5 gene frequencies among Moroccan blood donors, can serve as a background to diagnose the cause of FNAIT, PTP, and PTR and to provide HPA-matched platelet for patients with HPA alloimmune disorders. Although, larger studies are required to confirm this data.

\section{REFERENCES}

1. Leslie M. Cell biology. Beyond clotting: The powers of platelets. Science 2010 Apr 30;328(5978):562-4.

2. Semple JW, Italiano JE Jr, Freedman J. Platelets and the immune continuum. Nat Rev Immunol 2011 Apr;11(4):264-74.

3. Pai SC, Burnouf T, Chen JW, Lin LI. Human platelet antigen alleles in 998 Taiwanese blood donors determined by sequence-specific primer polymerase chain reaction. Biomed Res Int 2013;2013:973789.

4. Loghem J van, Dorfmeijer H, Hart M, Schreuder F. Serological and genetical studies on a platelet antigen (Zw). Vox Sang 1959 Apr;4(2):161-9.

5. Al-Ouda SK, Al-Banyan AA, Abdel Gader AG, Bayoumy NM, Al-Gahtani FH. Gene frequency of human platelet alloantigens- 1 to -6 and -15 in Saudi blood donors. Transfus Med 2016 Jun;26(3):220-4.

6. Silvestre APA, Zacarias JMV, Guelsin GAS, Visentainer JEL, Sell AM. Genetic polymorphisms of human platelet antigens in Euro-African and Japanese descendants from Parana, Southern Brazil. Platelets 2017 Sep;28(6):607-10.

7. Mangerona CM, Garcia FB, Moraes-Souza H. Frequency of human platelet antigens (HPA)-1, -2, -5 and -15 in Brazilian blood donors and establishment of a panel of HPA-typed donors. Transfus Med 2015 Jun;25(3):189-94.

8. Curtis BR, McFarland JG. Human platelet antigens 2013. Vox Sang 2014 Feb;106(2):93-102.

9. Rozman P. Platelet antigens: The role of human platelet alloantigens (HPA) in blood transfusion and transplantation. Transpl Immunol 2002 Aug;10(23):165-81.

10. Ghevaert C, Rankin A, Huiskes E, et al. Alloantibodies against low-frequency human platelet antigens do not account for a significant proportion of cases of fetomaternal alloimmune thrombocytopenia: Evidence from 1054 cases. Transfusion 2009 Oct;49(10):2084-9. 
11. Kaplan C. Immunologie plaquettaire et alloimmunisation post-transfusionnelle. Hématologie 1997;3(1):45-51.

12. Deckmyn H, Ulrichts $\mathrm{H}$, Van de Walle G, Vanhoorelbeke K. Platelet antigens and their function. Vox Sang 2004;87(s2):105-11.

13. Pappalardo PA, Secord AR, Quitevis P, Haimowitz MD, Goldfinger D. Platelet transfusion refractoriness associated with HPA-1a (Pl(A1)) alloantibody without coexistent HLA antibodies successfully treated with antigen-negative platelet transfusions. Transfusion 2001 Aug;41(8):984-7.

14. Bertrand G, Kaplan C. Genotyping applied to platelet immunology: When? How? Limits. [Article in French]. Transfus Clin Biol 2009 May;16(2):164-9.

15. Brecher ME. Technical Manual. Bethesda MD: American Association of Blood Banks; 2005.

16. Bhatti FA, Uddin M, Ahmed A, Bugert P. Human platelet antigen polymorphisms (HPA-1, -2, -3, -4, -5 and -15) in major ethnic groups of Pakistan. Transfus Med 2010 Apr;20(2):78-87.

17. Seo DH, Park SS, Kim DW, Furihata K, Ueno I, Han KS. Gene frequencies of eight human plateletspecific antigens in Koreans. Transfus Med 1998 Jun;8(2):129-32.

18. Spencer JA, Burrows RF. Feto-maternal alloimmune thrombocytopenia: A literature review and statistical analysis. Aust N Z J Obstet Gynaecol 2001 Feb;41(1):45-55.

19. Ferrer G, Muñiz-Diaz E, Aluja MP, et al. Analysis of human platelet antigen systems in a Moroccan Berber population. Transfus Med. 2002 Feb;12(1):49-54.

20. Hulley SB, Cummings SR, Browner WS, Grady DG, Newman TB. Designing Clinical Research. Philadelphia, USA: Lippincott Williams \& Wilkins; 2013.

21. Cavanagh G, Dunn AN, Chapman CE, Metcalfe P. HPA genotyping by PCR sequence-specific priming (PCR-SSP): A streamlined method for rapid routine investigations. Transfus Med 1997 Mar;7(1):41-5.

22. Feng ML, Liu DZ, Shen W, et al. Establishment of an HPA-1- to -16-typed platelet donor registry in China. Transfus Med 2006 Oct;16(5):369-74.

23. Chiba M, Suzuki S, Hinokio Y, et al. Tyrosine hydroxylase gene microsatellite polymorphism associated with insulin resistance in depressive disorder. Metabolism 200o Sep;49(9):1145-9.

24. Hod EA, Brittenham GM, Billote GB, et al. Transfusion of human volunteers with older, stored red blood cells produces extravascular hemolysis and circulating non-transferrin-bound iron. Blood 2011 Dec 15;118(25):6675-82.

25. Husebekk A, El Ekiaby M, Gorgy G, et al. Foetal/ neonatal alloimmune thrombocytopenia in Egypt; human platelet antigen genotype frequencies and antibody detection and follow-up in pregnancies. Transfus Apher Sci 2012 Dec;47(3):277-82.

26. Flug F, Karpatkin M, Karpatkin S. Should all pregnant women be tested for their platelet PLA (Zw, HPA-1) phenotype? Br J Haematol 1994 Jan;86(1):1-5.

27. Halle L, Bigot A, Mulen-Imandy G, et al. HPA polymorphism in sub-Saharan African populations: Beninese, Cameroonians, Congolese, and Pygmies. Tissue Antigens 2005 Mar;65(3):295-8.
28. Glade-Bender J, McFarland JG, Kaplan C, Porcelijn L, Bussel JB. Anti-HPA-3A induces severe neonatal alloimmune thrombocytopenia. J Pediatr 2001 Jun;138(6):862-7.

29. Lyou JY, Chen YJ, Hu HY, Lin JS, Tzeng CH. PCR with sequence-specific primer-based simultaneous genotyping of human platelet antigen-1 to $-13 \mathrm{w}$. Transfusion 2002 Aug;42(8):1089-95.

30. Zarati F, Achtak H, Moutia M, et al. Pattern of genetic diversity of $\mathrm{ABO}$ system in moroccan blood donors evidenced by model-based Bayesian clustering. Int $\mathrm{J}$ Innov Appl Stud 2017;19(4):750.

31. Ertel K, Al-Tawil M, Santoso S, Kroll H. Relevance of the HPA-15 (Gov) polymorphism on CD109 in alloimmune thrombocytopenic syndromes. Transfusion 2005 Mar;45(3):366-73.

32. Ghevaert C, Campbell K, Walton J, et al. Management and outcome of 200 cases of fetomaternal alloimmune thrombocytopenia. Transfusion 2007 May;47(5):901-10.

33. Brouk H, Halle L, Bertrand G, Neche FZ, Ouelaa H, Kaplan C. Human platelet antigen allele frequencies in different Algerian populations. Tissue Antigens 2010 Jun;75(6):673-8.

34. Hadhri S, Gandouz R, Chatti N, Bierling P, Skouri H. Gene frequencies of the HPA-1 to -6 and -15 human platelet antigens in Tunisian blood donors. Tissue Antigens 2010 Sep;76(3):236-9.

35. Salem AH, Abdel Hamed AE, Abdalla EM, Almawi W. Gene frequencies of human platelet alloantigens 1-5 in two Arab populations. Blood Transfus 2014 Jan;12 Suppl 1:s281-5

36. Mérieux Y, Debost M, Bernaud J, Raffin A, Meyer F, Rigal D. Human platelet antigen frequencies of platelet donors in the French population determined by polymerase chain reaction with sequence-specific primers. Pathol Biol (Paris) 1997 Nov;45(9):697-700.

37. Bontadini A, Tazzari PL, Manfroi S, Ruscitto MC, Fruet F, Conte R. Human-platelet-antigen and neutrophil-antigen gene frequency in the Italian population determined by polymerase chain reaction with sequence specific primers. Haematologica 2000 Apr;85(4):430-1.

38. Chen DF, Pastucha LT, Chen HY, Kadar JG, Stangel W. Simultaneous genotyping of human platelet antigens by hot start sequence-specific polymerase chain reaction with DNA polymerase AmpliTaq Gold. Vox Sang 1997;72(3):192-6.

39. Portela CN, Schriefer A, Albuquerque SR, Perdomo RT, Parente AF, Weber SS. The human platelet alloantigen profile in blood donors from Amazonas, Brazil. Transfus Med 2016 Dec;26(6):448-56.

40. Bennett JA, Palmer LJ, Musk AW, Erber WN. Gene frequencies of human platelet antigens 1-5 in indigenous Australians in Western Australia. Transfus Med 2002 Jun;12(3):199-203.

41. Tanaka S, Ohnoki S, Shibata H, Okubo Y, Yamaguchi $\mathrm{H}$, Shibata Y. Gene frequencies of human platelet antigens on glycoprotein IIIa in Japanese. Transfusion 1996 Sep;36(9):813-7. 


\section{Acknowledgements}

The authors express their thanks to the blood donors of Regional Blood Transfusion Center of Casablanca. Laboratory of Hematology Cell and Genetic Engineering Faculty of Medicine and Pharmacy Casablanca University Hassan II Morocco Team, and to the National Blood Transfusion Centre of Rabat Morocco

\section{Author Contributions}

Zainab Ouabdelmoumene - Substantial contributions to conception and design, Acquisition of data, Analysis and interpretation of data, Drafting the article, Revising it critically for important intellectual content, Final approval of the version to be published

Houria EL Housse - Substantial contributions to conception and design, Acquisition of data, Analysis and interpretation of data, Drafting the article, Revising it critically for important intellectual content, Final approval of the version to be published

Fatima Zarati - Substantial contributions to conception and design, Acquisition of data, Analysis and interpretation of data, Drafting the article, Revising it critically for important intellectual content, Final approval of the version to be published

Nadia Nourichafi - Substantial contributions to conception and design, Acquisition of data, Analysis and interpretation of data, Drafting the article, Revising it critically for important intellectual content, Final approval of the version to be published

Kamal Bouisk - Substantial contributions to conception and design, Acquisition of data, Analysis and interpretation of data, Drafting the article, Revising it critically for important intellectual content, Final approval of the version to be published
Mohamed Benajiba - Substantial contributions to conception and design, Acquisition of data, Analysis and interpretation of data, Drafting the article, Revising it critically for important intellectual content, Final approval of the version to be published

Norddine Habti - Substantial contributions to conception and design, Acquisition of data, Analysis and interpretation of data, Drafting the article, Revising it critically for important intellectual content, Final approval of the version to be published

\section{Guarantor of Submission}

The corresponding author is the guarantor of submission.

\section{Source of Support}

None

\section{Consent Statement}

Written informed consent was obtained from the patient for publication of this study.

\section{Conflict of Interest}

Authors declare no conflict of interest.

\section{Copyright}

(C) 2018 Zainab Ouabdelmoumene et al. This article is distributed under the terms of Creative Commons Attribution License which permits unrestricted use, distribution and reproduction in any medium provided the original author(s) and original publisher are properly credited. Please see the copyright policy on the journal website for more information.
Access full text article on other devices

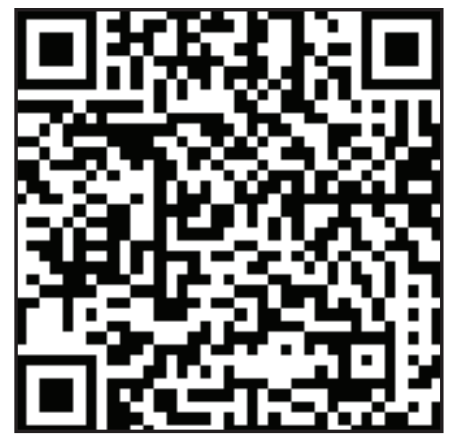

Access PDF of article on other devices

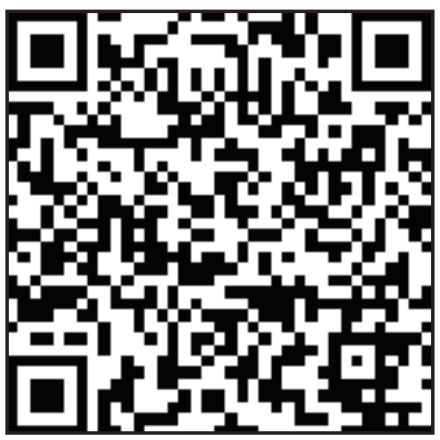

